\title{
The Ångström Exponent and Turbidity of Soot Component in the Radiative Forcing of Urban Aerosols
}

*D.O. Akpootu and M. Momoh

Department of Physics, Usmanu Danfodiyo University, Sokoto, Nigeria [Corresponding author: Email; profdon03@yahoo.com, 盈: +2347038918403]

ABSTRACT: In this work, we extracted data from Optical Properties of Aerosols and Clouds (OPAC) using FORTRAN program to model the effect of soot on optical depth, scattering coefficient, absorption coefficient, single scattering albedo, extinction coefficient and asymmetry parameter at spectral range of 0.25 to $1.00 \mu \mathrm{m}$ for eight different relative humidities (RHs) $(0,50,70,80,90,95,98$ and $99 \%)$. The concentration of sootwas varied as $1.10 \times 10^{5}, 1.20 \times 10^{5}$ and $1.30 \times 10^{5} \mathrm{~cm}^{-3}$ while the insoluble and water soluble were kept constant at 1.50 and $15,000 \mathrm{~cm}^{-3}$ respectively. The optical parameters were used to determine the Radiative forcing (RF). Origin 50 software was used to plot the graphs. SPSS 16.0 Software was used to determine the Angström exponent, $\alpha$ and Curvature, $\alpha_{2}$. The $\alpha$ reflects the dominance of fine-mode particles while $\alpha_{2}$ at $0 \% \mathrm{RH}$ reflects the dominance of coarse-mode particles and at $50-99 \% \mathrm{RHs}$ reflects the dominance of fine-mode particles, the turbidity, $\beta$ indicates a relatively hazy atmosphere, the Aerosol Optical Depth (AOD) show a relatively higher value indicating a polluted urban air, the asymmetry parameter, $g$ falls between 0.64 and 0.77 . However, from our graphs of Radiative forcing against wavelength, we report that addition of soot concentration reflects warming effect; therefore soot has a relatively high absorption coefficient.

Keywords: Soot, Angström exponent, Turbidity, Radiative forcing, Aerosols

\section{INTRODUCTION}

During the recent decade a great deal of effort has been devoted to establishing the effects of aerosols on global, as well as regional climate. Aerosols particles affect the global radiation budget directly through back scattering or absorption of solar radiation (Kaufman et al., 1998, 2002). They can also affect the radiation budget and the regional water cycle through inducing changes in the microphysical properties of clouds by acting as cloud droplet condensation nuclei (Kaufman et al., 2002; Lohmann and Feichter, 2005). This is often referred to as the indirect radiative effect of aerosols on climate and is today the largest uncertainty in predicting the future global climate (Intergovernmental panel on climate change, 2001).

Soot in combustion products of hydrocarbon fuels has a complex chemical composition. In soot, 97$99 \%$ of the mass is carbon, but soot also contains hydrocarbons and other substances (Ramanathan and Crutzen, 2003). Out of many species of aerosols which induce direct radiativeforcing, black Carbon (BC) play a major role in the forcing by partly shielding the surface from the intense tropical solar radiation (Ramanathan and Crutzen, 2003). BC aerosols have been found to be contributing significantly to the atmospheric warming both globally and regionally (Ramanathan and Carmichael, 2008).
Light scattering by aerosols particles result in a negative radiative forcing (cooling effect), as part of the solar flux is scatter back to space. If the particles contain absorbing material, total forcing can become positive (heating effect or warming effect), as the energy absorbed by the particles leads to an increase of thermal radiation (Haywood and Shine, 1995).Aerosols affect the Earth's temperature and climate by altering the radiative properties of the atmosphere. A large positive component of this radiative forcing from aerosols is due to black carbon-soot- that is released from the burning of fossil fuel and biomass, and to a lesser extent, natural fires (Jacobson, 2001).

The role of soot particles in combustion remains as one of the main motivations of both experimental and theoretical studies of soot radiative properties. The formation of soot, the chemical composition, and the morphology of soot particles have been studied experimentally over the years and there is a body of research on this subject (Pickett and Siebers, 2004; Van der Wal and Tomasek, 2004; Lombaertet al., 2006; Lockett and Woolley, 2007; Watanabe et al., 2008). There are also some attempts of theoretical modeling of soot formation (Wen et al., 2003;Balthasar and Frenklach, 2005; Lignellet al., 2007; Paterson and Kraft, 2007).

However, in this paper we model the effect of soot on optical depth, scattering coefficient, absorption 
coefficient, single scattering albedo, extinction coefficient and asymmetry parameter at spectral range of 0.25 to $1.00 \mu \mathrm{m}$ for eight different relative humidities (RHs) $(0,50,70,80,90,95,98$ and 99\%). The spectral range was chosen because it covers the wavelength of the visible region.

\section{MODELING DETAILS}

The models extracted from OPAC are given in Table 1.

Table 1: Compositions of aerosols types

\begin{tabular}{llll}
\hline Components & Model $1 \mathrm{a}$ & Model $1 \mathrm{~b}$ & Model $1 \mathrm{c}$ \\
\hline Insoluble & 1.50 & 1.50 & 1.50 \\
water soluble & $15,000.00$ & $15,000.00$ & $15,000.00$ \\
Soot & $110,000.00$ & $120,000.00$ & $130,000.00$ \\
Total & $125,001.50$ & $135,000.00$ & $145,001.50$ \\
\hline
\end{tabular}

Source: Hess et al. (1998).

THE RADIATIVE FORCING MODEL AND ÅNGSTRÖM EXPONENT

The data used for the urban aerosols in this work are derived from the Optical Properties of Aerosols and Clouds (OPAC) data set (Hess et al., 1998). In this, a mixture of three components is used to describe Urban aerosols. a water soluble components (WASO), consists of scattering aerosols, that are hygroscopic in nature, such as sulphates and nitrates present in anthropogenic pollution, water insoluble (INSO) and soot (SOOT), not soluble in water and therefore the particles are assumed not to grow with increasing relative humidity.

To estimate the radiativeforcing using a simple model.Chylek and Wong (1995) derived the formula that can be used to calculate the globally averaged direct aerosol Radiative forcing of absorbing aerosols, $\Delta \mathrm{F}_{\mathrm{R}}$, as.

$\Delta F_{R}=-\frac{s_{0}}{4} T_{\text {atm }}^{2}\left(1-N_{\text {cloud }}\right) 2 \tau\{(1-$ $\left.a)^{2} \beta \omega-2 a(1-\omega)\right\} \ldots$ (1)

where $\mathrm{S}_{0}$ is the solar constant, $\mathrm{T}_{\mathrm{amm}}$ is the transmittance of the atmosphere above the aerosol layer, $\mathrm{N}_{\text {cloud }}$ is the fraction of the sky covered by clouds, $\tau$ is the aerosol optical depth, $\omega$ is the average single scattering albedo of the aerosol layer, $a$ is the albedo of the underlying surface and $\beta$ is the fraction of radiation scattered by aerosol into the atmosphere. The above expression gives the radiative forcing due to the change of reflectance of the earth-aerosol system. The upscattering fraction is calculated using an approximate relation (Sagan and Pollack, 1967)

$\beta=\frac{1}{2}(1-\mathrm{g})$ where $g$ is the asymmetry parameter of the aerosol layer.

This model for the radiative forcing assumes that the aerosols are optically thin and that there is no radiative forcing where clouds are present. Although it is very simple, the model has been shown to provide reasonable estimates for the radiative forcing by both sulphate aerosols (Charlsonet al., 1992) and absorbing smoke and soot aerosols (Chylek and Wong, 1995).

The spectral behavior of the aerosols optical depth ( $\mathrm{T})$ (or scattering $\left(\sigma_{\text {scat }}\right)$, absorption $\left(\sigma_{\text {abs }}\right)$ and extinction $\left(\sigma_{\text {ext }}\right)$ coefficients) can be used to obtain some information regarding the size distribution by just looking at the Angström coefficient exponent that expresses the spectral dependence of any of the optical parameters with the wavelength of light $(\lambda)$ as inverse power law (Ångström, 1961; Ångström, 1929).

$T(\lambda)=\beta \lambda^{-a}$

The wavelength dependence of $T(\lambda)$ can be characterized by the Angström parameter, which is a coefficient of the following regression.

$\ln (\lambda)=-a \ln (\lambda)+\ln \beta$

where $\beta$ and $\alpha$ are the turbidity coefficient and the shaping factor, respectively.(Liou, 2002; O'Neill and Roer, 1993).

The shaping factor, $a$ is also related to the size of particles. So $\alpha$ and $\beta$ can be used to describe the size distribution of aerosol particles and the general haziness of the atmosphere respectively. Larger particles generally correspond to smaller $a$, whereas smaller particles generally correspond to larger $a$.

The Angström exponent itself varies with avelength, and a more precise empirical relationship between aerosol extinction and wavelength is obtained with a 2nd-order polynomial (King and Byrne, 1976; Eck et al., 1999; Eck. et al., 2001a, b, 2003; Kaufman, 1993; O'Neillet al., 2001, 2003) as.

$\operatorname{lnt}(\lambda)=a_{2}(\ln \lambda)^{2}+a_{1} \ln \lambda+\ln \beta$

Here, the coefficient $a_{2}$ accounts for a "curvature" often observed in sunphotometry measurements. In case of negative curvature $\left(a_{2}<0\right.$, convex type curves) the rate of change of $a$ is more significant at the longer wavelengths, while in case of positive curvature ( $a_{2}>0$, concave type curves) the rate of change of $a$ is more significant at the shorter wavelengths (Kaufman, 1993; Eck et al., 1999; Eck. 
et al., 2001b; Reid et al., 1999). Eck et al. (1999) reported the existence of negative curvatures for fine-mode aerosols and positive curvatures for significant contribution by coarse-mode particles in the size distribution.

\section{RADIATIVE FORCING MODEL ESTIMATES}

The radiative forcing model given in equations (1) and (2) are used to estimate the globally averaged radiative forcing due to soot and water soluble of urban aerosols. The model parameters are assigned the following values. $\mathrm{S}_{0}=1368 \mathrm{Wm}^{-2}, \mathrm{~T}_{\mathrm{atm}}=0.79$ (Penneret al., 1992), $\mathrm{N}_{\text {cloud }}=0.6$ and the surface albedo which varies from 0.06 for the ocean to 0.22 for the global land. However, in this work $a=0.22$. The optical properties; extinction coefficient, scattering coefficient, absorption coefficient, asymmetry parameter and optical depth at RHs (0, $50,70,80,90,95,98$ and $99 \%$ ) at spectral range of 0.25 to $1.00 \mu \mathrm{m}$ are used in this model.

\section{THE ANGSTRÖM TURBIDITY COEFFICIENT ( $\beta$ )}

Wavelength, optical thickness, and atmospheric turbidity (haziness) are related through Ångstrom's turbidity formula.

$T=\beta \cdot \lambda-\alpha$

where $\beta$ is Angstrom's turbidity coefficient, $\lambda$ is wavelength in microns, and $\alpha$ is the Angstrom exponent.

$a$ and $\beta$ are independent of wavelength, and can be used to describe the size distribution of aerosol particles and the general haziness of the atmosphere. For two different wavelengths,

$\mathrm{T}_{1}=\beta \cdot \lambda_{1}-\mathrm{a}$

$\mathrm{T}_{2}=\beta \cdot \Lambda_{2}{ }^{-\alpha}$

from which

$$
\frac{\tau_{1}}{\lambda_{1}^{-\alpha}}=\frac{\tau_{2}}{\lambda_{2}^{-\alpha}}
$$

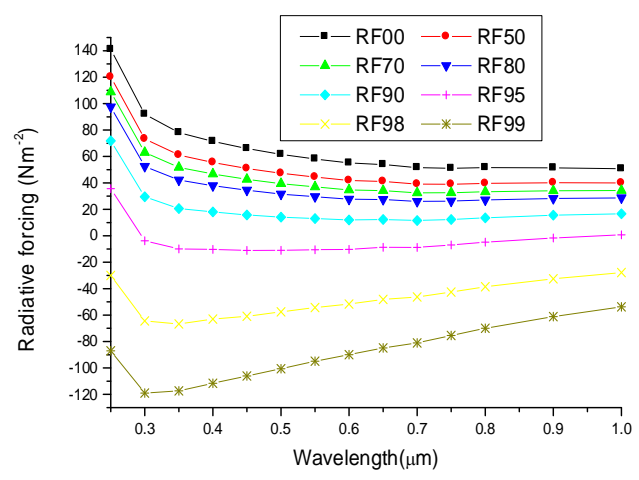

Figure 1. A graph of radiative forcing against wavelength
Solving for $a$.

$$
\alpha=\frac{\ln \left(\frac{\tau_{1}}{\tau_{2}}\right)}{\ln \left(\frac{\lambda_{2}}{\lambda_{1}}\right)}
$$

For each wavelength, $\beta$ is determined as.

$$
\beta=\mathrm{T}_{1} \bullet \lambda_{1}{ }^{a}=\mathrm{T}_{2} \cdot{ } \lambda_{2}{ }^{\mathrm{a}}
$$

where $\lambda$ must be expressed in microns $(500 \mathrm{~nm}=$ $0.500 \mu$ ). $\beta$ values of less than 0.1 are associated with a relatively clear atmosphere, and values greater than 0.2 are associated with a relatively hazy atmosphere.

\section{RESULTS AND DISCUSSION}

To analyse the effect of soot components in Radiative forcing (RF) of urban aerosols we see from Table1 Composition of aerosol types in it insoluble and water soluble are kept constant at 1.50 and 15,000 respectively, while the concentration of soot varies from $1.10 \times 10^{5}, 1.20 \times 10^{5}$ and $1.30 \times 10^{5} \mathrm{~cm}^{-3}$ This effect is observed in Figure 1, Figure 2, Figure 3, Figure 4, Figure 5, Figure 6, Figure 7, Figure 8 and Figure 9. By considering the graphs of Radiative forcing against wavelength shown in Figure 1, Figure 4 and Figure 7 we observed that at $0-99 \% \mathrm{RHs}$ the Radiative forcing is positive which reflects warming effect. The relation of RF with wavelength is such that it decreases with wavelength from $0-90 \%$ Relative Humidity $(\mathrm{RH})$ in the form of power law, and tend to increase in a concave quadratic form from $95-99 \% \mathrm{RH}$ from the graph it was observed that the RF decreases with increase in RH. Thus, the effect of adding soot reflects warming on the Earth's atmosphere, therefore, it is closely related to the greenhouse gases.

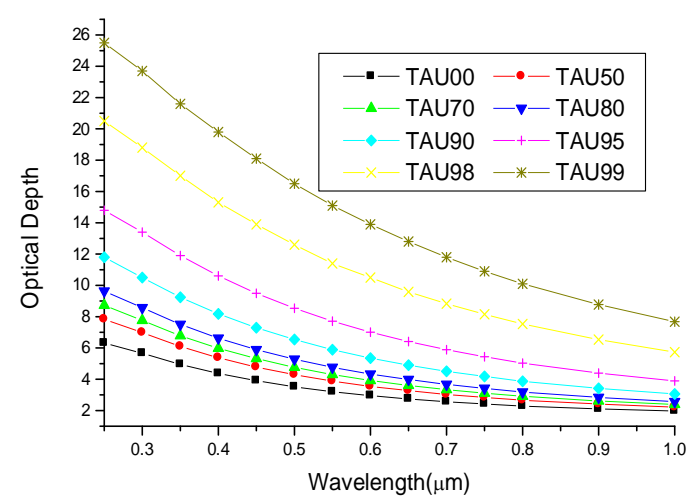

Figure 2: A graph of optical depth against wavelength 
Table 2. The results of the Ångström coefficients for Model 1a using equations (4) and (5) at the respective relative humidities using regression analysis with SPSS16.0.

\begin{tabular}{cccc|cccc}
\multicolumn{5}{c|}{ Linear } & \multicolumn{5}{c}{ Quadratic } \\
\hline $\mathrm{RH}(\%)$ & $\mathrm{R}^{2}$ & $\mathrm{a}$ & $\beta$ & $\mathrm{R}^{2}$ & $\mathrm{a}_{1}$ & $\mathrm{a}_{2}$ & $\beta$ \\
\hline 0 & 0.99716 & 0.88942 & 1.89869 & 0.99718 & -0.87478 & 0.01074 & 1.90477 \\
50 & 0.99767 & 0.95463 & 2.18600 & 0.99807 & -1.01951 & -0.04759 & 2.15528 \\
70 & 0.99731 & 0.97719 & 2.37797 & 0.99839 & -1.08704 & -0.08058 & 2.32166 \\
80 & 0.99666 & 0.99232 & 2.59259 & 0.99868 & -1.14479 & -0.11185 & 2.50777 \\
90 & 0.99444 & 1.00563 & 3.15204 & 0.99913 & -1.24161 & -0.17311 & 2.99387 \\
95 & 0.99054 & 0.99513 & 4.10309 & 0.99951 & -1.31856 & -0.23726 & 3.82356 \\
98 & 0.98330 & 0.94069 & 6.21860 & 0.99982 & -1.35728 & -0.30560 & 5.67836 \\
99 & 0.97709 & 0.88316 & 8.44252 & 0.99991 & -1.34429 & -0.33827 & 7.63453 \\
\hline
\end{tabular}
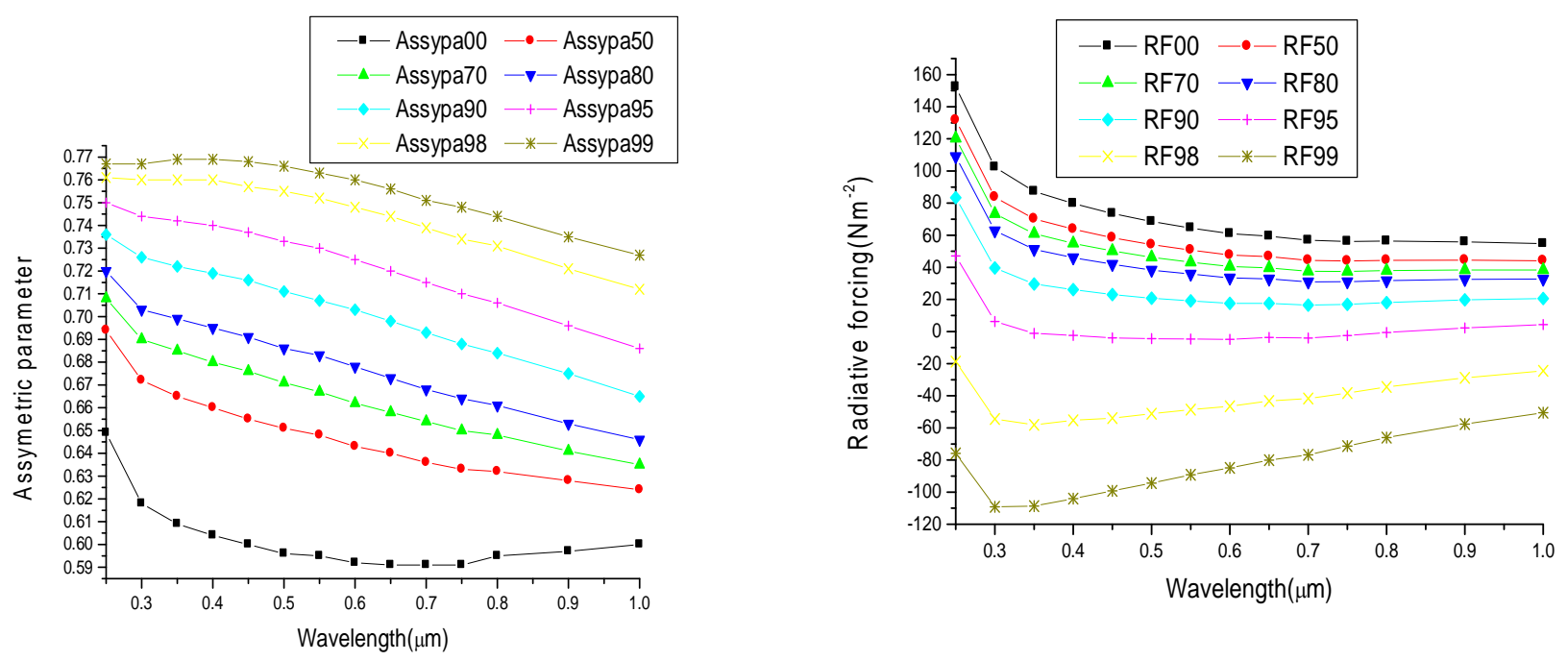

Figure 3: A graph of asymmetric parameter against wavelength Figure 4: A graph of radiative forcing against wavelength

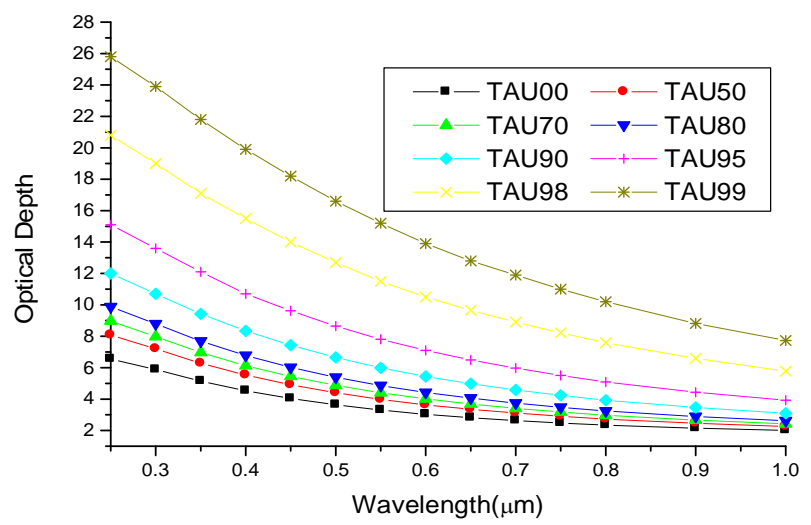

Figure 5: A graph of optical depth against wavelength 
Akpootu and M. Momoh: The Angström exponent and turbidity of soot component in the Radiative forcing of ......

Table 3: The results of the Ångström coefficients for Model $1 \mathrm{~b}$ using equations (4) and (5) at the respective relative humidities using regression analysis with SPSS16.0.

\begin{tabular}{rlll|llll}
\hline \multicolumn{5}{c}{ Linear } & \multicolumn{4}{c}{ Quadratic } \\
\hline $\mathrm{RH}(\%)$ & $\mathrm{R}^{2}$ & $\alpha$ & $\beta$ & $\mathrm{R}^{2}$ & $\mathrm{a}_{1}$ & $\mathrm{a}_{2}$ & $\beta$ \\
\hline 0 & 0.99715 & 0.90177 & 1.943251 & 0.99716 & -0.8917 & 0.007389 & 1.94753 \\
50 & 0.99760 & 0.96343 & 2.230815 & 0.99803 & -1.03138 & -0.04985 & 2.19800 \\
70 & 0.99726 & 0.98463 & 2.422911 & 0.99836 & -1.09634 & -0.08194 & 2.36458 \\
80 & 0.99664 & 0.99871 & 2.637723 & 0.99865 & -1.15178 & -0.11229 & 2.55110 \\
90 & 0.99451 & 1.01104 & 3.196606 & 0.99910 & -1.24570 & -0.17214 & 3.03708 \\
95 & 0.99070 & 0.99927 & 4.147965 & 0.99950 & -1.32093 & -0.23596 & 3.86687 \\
98 & 0.983532 & 0.94394 & 6.263338 & 0.99980 & -1.35874 & -0.30429 & 5.72144 \\
99 & 0.977451 & 0.88640 & 8.485223 & 0.99991 & -1.34539 & -1.34539 & 7.67674 \\
\hline
\end{tabular}

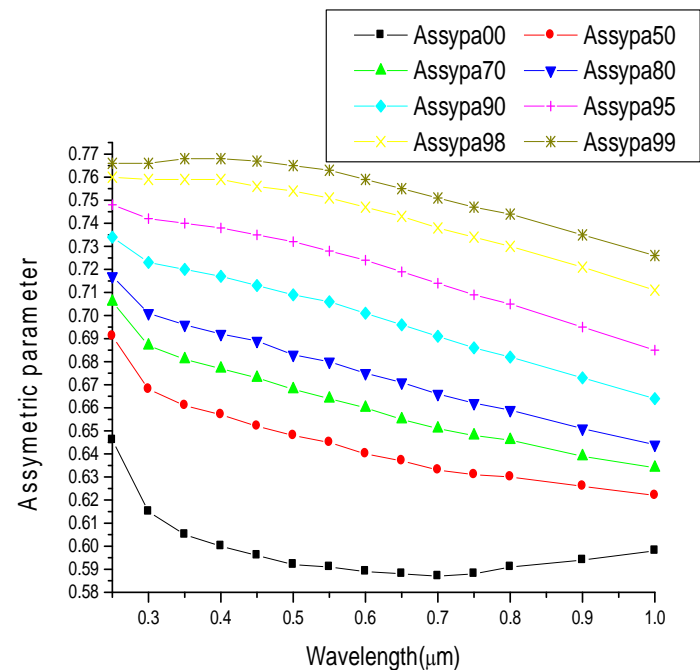

Figure 6: A graph of asymmetric parameter against wavelength

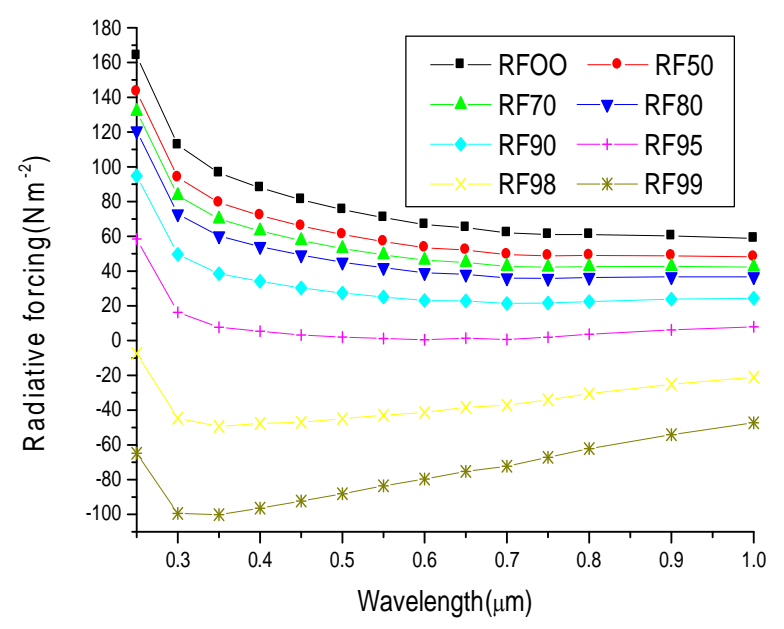

Figure 7: A graph of radiatiive forcing against wavelength

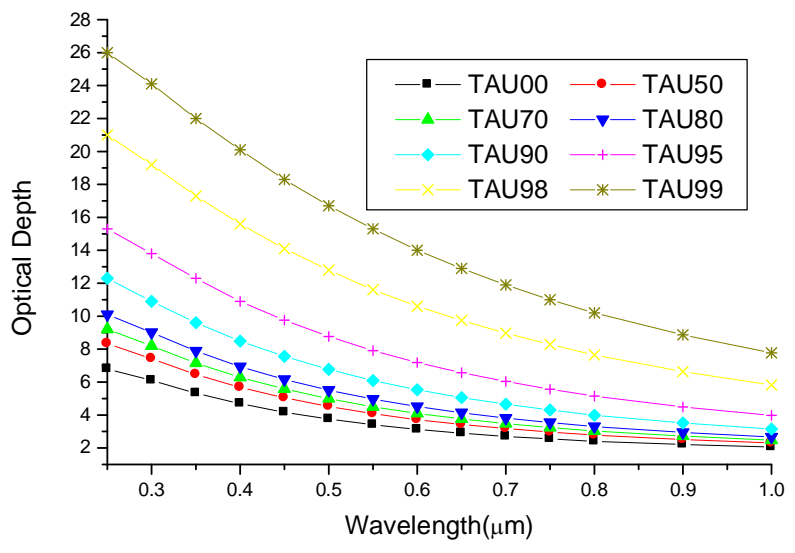

Figure 8: A graph of optical depth against wavelength 
Table 4. The results of the Angström coefficients for Model $1 \mathrm{c}$ using equations (4) and (5) at the respective relative humidities using regression analysis with SPSS16.0.

\begin{tabular}{cccc|cccc}
\hline \multicolumn{4}{c}{ Linear } & \multicolumn{4}{c}{ Quadratic } \\
\hline $\mathrm{RH}(\%)$ & $\mathrm{R}^{2}$ & $\alpha$ & $\beta$ & $\mathrm{R}^{2}$ & $\mathrm{a}_{1}$ & $\mathrm{a}_{2}$ & $\beta$ \\
\hline 0 & 0.99714 & 0.91350 & 1.98778 & 0.99714 & -0.90855 & 0.00363 & 1.98992 \\
50 & 0.99755 & 0.97173 & 2.27574 & 0.99800 & -1.04255 & -0.05196 & 2.24085 \\
70 & 0.99721 & 0.99172 & 2.46781 & 0.99833 & -1.10516 & -0.08322 & 2.40748 \\
80 & 0.99664 & 1.00504 & 2.68255 & 0.99863 & -1.15845 & -0.11253 & 2.59426 \\
90 & 0.99456 & 1.01606 & 3.24145 & 0.99908 & -1.25010 & -0.17168 & 3.08011 \\
95 & 0.99084 & 1.00343 & 4.19279 & 0.99947 & -1.32329 & -0.23464 & 3.91019 \\
98 & 0.98381 & 0.94737 & 6.30763 & 0.99979 & -1.35989 & -0.30261 & 5.76477 \\
99 & 0.97783 & 0.88921 & 8.53057 & 0.99990 & -1.34568 & -0.33485 & 7.72200 \\
\hline
\end{tabular}

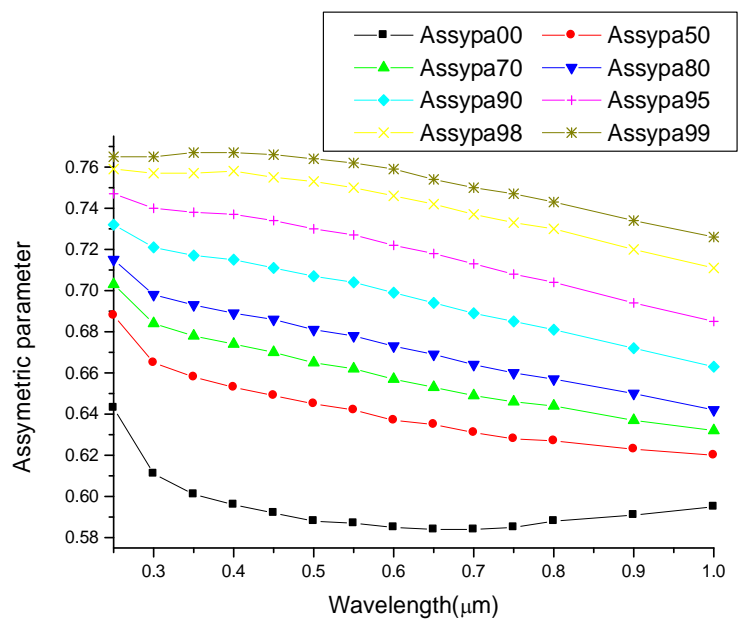

Figure 9: A graph of asymmetric parameter against wavelength

To analyse the effect of soot components in Radiative forcing (RF) of urban aerosols we see from Table1 Composition of aerosol types in it insoluble and water soluble are kept constant at 1.50 and 15,000 respectively, while the concentration of soot varies from $1.10 \times 10^{5}, 1.20 \times 10^{5}$ and $1.30 \times 10^{5} \mathrm{~cm}^{-3}$ This effect is observed in Figure 1, Figure 2, Figure 3, Figure 4, Figure 5, Figure 6, Figure 7, Figure 8 and Figure 9. By considering the graphs of Radiative forcing against wavelength shown in Figure 1, Figure 4 and Figure 7 we observed that at $0-99 \%$ RHsthe Radiative forcing is positive which reflects warming effect. The relation of RF with wavelength is such that it decreases with wavelength from $0-90 \%$ Relative Humidity $(\mathrm{RH})$ in the form of power law, and tend to increase in a concave quadratic form from $95-99 \% \mathrm{RH}$ from the graph it was observed that the RF decreases with increase in $\mathrm{RH}$. Thus, the effect of adding soot reflects warming on the Earth's atmosphere, therefore, it is closely related to the greenhouse gases.

To analyse the effect of Ångström exponent $(\alpha)$ on the linear part and Curvature on the quadratic part shown in Tables 2, Table 3 and Table 4 from this, we observed that the $\alpha$ increase with $\mathrm{RH}$ from 0 $90 \% \mathrm{RH}$ and decreases from $95-99 \% \mathrm{RH}$. Eck et al., (1999; 2001) and Ranjanet al.,( 2007) reported that large positive values of Angström exponent $\alpha$ are characteristics of fine-mode-dominated aerosols size distributions while near zero and negative values are characteristics of dominant coarse-mode or bi-modal size distributions, with coarse-mode aerosols having significant magnitude (Eck et al., 1999; O'Neill et al., 2001; Kaskaoutis and Kambezidis, 2006). In case of negative curvature $\left(a_{2}<0\right.$, convex type curves) the rate of change of $a$ is more significant at the longer wavelengths, while in case of positive curvature $\left(a_{2}>0\right.$, concave type curves) the rate of change of $a$ is more significant at 
the shorter wavelengths (Kaufman, 1993; Eck et al., 1999; Eck. et al., 2001b; Reid et al., 1999). Eck et al., (1999) reported the existence of negative curvatures for fine-mode aerosols and positive curvatures for significant contribution by coarsemode particles in the size distribution.

In our case, at $0 \% \mathrm{RH}$, in Tables 2, 3 and 4 the values of the $\alpha$ reflects the dominance of fine mode particles, but, at the quadratic part it shows the dominance of coarse mode particles, because $\alpha_{2}>0$ from $50-99 \% \mathrm{RH} \quad \alpha_{2}$ becomes negative and increases in magnitude at higher $\mathrm{RH}$ as shown in the tables. The negative value in $\alpha_{2}$ implies the dominance of fine mode particles. The presence of fine and coarse mode particles shows that atmospheric aerosols are rarely monomodal (Whistby, 1978). Thus, they contain a wide range of sizes and are termed polydisperse aerosols. The graphs of optical depth against wavelength (Figures 2, 5 and 8) shows that optical depths follow a relatively smooth decrease with the increase in wavelength though some are steeper than others and the steepness increases with the increase in RHs. It is evident from the figures that there is a relatively strong wavelengths dependence of optical depths at shorter wavelengths that decreases toward longer wavelengths irrespective of the $\mathrm{RH}$, attributing to the presence of fine and coarse particles. The presence of fine mode particles which are selective scatters enhanced the irradiance scattering in shorter wavelength only while the coarse mode particles provide similar contributions to the optical depths at both wavelengths (Schuster et al., 2006). Additionally, fine particles scatter more lights in the forward direction than coarse particles.

In relation to $\mathrm{RH}$, it shows that optical depths increase with the increase in $\mathrm{RH}$. As the $\mathrm{RH}$ increases the optical depths continue to increase due to the increase in concentration of fine mode particles as a result of the continue sedimentation of coarse particles due to the increase in $\mathrm{RH}$. And also as the $\mathrm{RH}$ increases there is an increase in hygroscopic growth more to fine particles than coarse particles and since fine particles scatter more lights in the forward direction than coarse particles, that is why the optical depth are higher at shorter wavelengths than longer wavelengths even at higher $\mathrm{RH}$.

It also shows monomode type of particle size distributions in the form of Junge power law in this spectral range (Eck et al., 1999) and increase in $\mathrm{RH}$ has caused increase in mode growth because of the increase in optical depths. The increase of AOD with $\mathrm{RH}$ at the deliquescence point (90 to 99\%) is that the growth increase substantially, making the process strongly nonlinear with RH (Fitzgarald, 1975; Tang, 1996). These hygroscopic growth behaviours also reveal an immense potential of light scattering enhancement in the forward direction at high humidities and the potential for being highly effective cloud condensation nuclei. Reuder and Schwander (1999) reported that AOD typically varies between 0 and 1 in the UV wavelengths in a relatively clean atmosphere in a rural location but can be higher in polluted urban air. In this study, the AOD varies between 6 and 26 as shown from our figures which shows arelatively higher values indicating a polluted urban air. Using equation (10) and (11), we compute the value for the turbidity and obtain value greater than 0.2 indicating a relatively hazy atmosphere.

Figure 3, 6 and 9 show the graphs of asymmetric parameter ( $g$ ) against wavelength, it shows that smaller particles scatter more light than the bigger particles, it also shows that there is a dominance of fine particles because the asymmetry parameter does not change much with wavelength even as a result of hygroscopic growth. Madronich and Flocke (1997) reported that when $\mathrm{g}=1$ it indicates complete forward scattering, $g=-1$ indicates complete backward scattering and $g=0$ indicates isentropic scattering For UV wavelength $g$ typically falls between 0.6 and 0.8 . In our case $g$ falls between 0.64 and 0.77 which is in close agreement with that reported by Madronich and Flocke (1997).

\section{CONCLUSION}

In this research work, we are able to model the effect of soot and water soluble components in Radiative forcing (RF) of urban aerosols using data extracted from Optical Properties of Aerosols and Clouds (OPAC) and FORTRAN Software. The analysis of Ångström exponent, $\alpha$ and Curvature $\alpha_{2}$ at eight different relative humidities $(\mathrm{RHs})(0,50,70$, 80, 90, 95, 98 and 99\%) was done using SPSS 16.0 Software. Graphs were plotted using Origin 50 Software for the optical properties; optical depth against wavelength, asymmetric parameter against wavelength, and RF against wavelength for the eight different RHs at spectral range of 0.25 to $1.00 \mu \mathrm{m}$. Our study suggest that, soot has a relatively high absorption coefficient in RF of urban aerosols, thereby having warming effect; this effect is closely related to that of greenhouse gases in terms of warming the Earth's atmosphere by absorption of solar radiation. The AOD typically varies between 6 and 26 indicating a polluted urban air. In this study, 
the Angström exponent, $\alpha$ and the curvature $\alpha_{2}$ reveals that the atmospheric aerosols is composed of both fine and coarse mode particles. The turbidity, $\beta$, shows that the urban aerosols are associated with a relatively hazy atmosphere.

\section{REFERENCES}

Angström, A (1929). On the atmospheric transmission of Sun radiation and on dust in the air. GeografiskaAnnaler, 11: 156-166

Angström, A (1961). Techniques of determining the turbidity. Tellus, 13(2): 214-223.

Balthasar, M and Frenklach, M (2005). Detailed kinetic modeling of soot aggregate Formation in laminar premixed flames. Combustion Flame, 140: $130-145$

Charlson, R.J., Schwartz, S.E., Hales, J. M., Cess, R. D., Coakley, J. A., Hansen, J. E and Hotmann, D.J (1992). Climate forcing by anthropogenic aerosols, Science, 255: 423-430

Chylek, P and Wong, J (1995). Effect of absorbing aerosols on global radiation clouds of Venus. Journal of Geophysical Research, 72: 469-477.

Conant, W.C., Nenes, A., Seinfeld, J.H. (2002). Black carbon radiative heating effects on cloud microphysics and implication for aerosol indirect forcing. Journal of Geophysical research, $107 \mathrm{D}(24)$

Eck, T.F., Holben, B.N., Slutsker, I. and Setzer, A. (1998). Measurements of irradiance attenuation and estimation of aerosol single scattering albedo for biomass burning aerosols in Amazonia. Journal of Geophysical Research 103(31): 865-878

Eck, T.F., Holben, B.N., Ward, D.E., Dubovic, O., Reid, J.S., Smirnov, A., Mukelabai, M.M., Hsu, N.C., O'Neill, N.T. and Slutsker, I (2003). Characterization of the optical properties of Biomass Burning Aerosols in Zambia during the 1997 ZIBBEE Field. campaign Journal of Geophysical Research, 106: 3425-2448.

Eck, T.F., Holben, B. N., Dubovik, O., Smirnov, A., Slutsker, I., Lobert, J. M and Ramanathan, V. (2001a). Column- integrated aerosol optical properties over the Maldives during the Northern monsoon for 1998-2000, Journal of Geophysical Research 106(D22): 2855528566.

Eck, T.F. ,Holben, B.N., Ward, D.E., Dubovik, O., Reid, J.S., Smirnov, A., Mukelabai, M.M., Hsu, N.C., O'Neill, N.T. and Ramanathan, V. (2001b). Characterization of the optical properties of biomass burning aerosols in Zambia during the 1997 ZIBBEE field campaign. Journal of Geophysical Research 106: 3425-3448.

Eck, T.F., Holben, B.N., Reid, J.S., Dubovik, O., Smirnov, A., O'Neill, N.T., Slutsker, I. and Kinne, S (1999). Wavelength dependence of the optical depth of biomass burning, urban and desert dust aerosols. Journal of Geophysical Research, 104: 333- 349.

Fitzgerald, J.W. (1975). Approximation formulas for the equilibrium size of an Aerosol particle as a function of its dry size, composition and ambient. Geophysical Research, 98(D2): 26772692.

Haywood, J.M and Shine, K.P. (1995). The effect of Anthropogenic sulphate and soot aerosol on the clear sky planetary radiation budget, Journal of Geophysical Research, 22(5): 603606.

Hess, M., Koepke, P and Schult, I (1998). Optical Properties of Aerosols and Clouds. American Meteorology Society.

Intergovernmental Panel on climate change (IPCC) (2001). Climate change, Third Assessment Report, Scientific Basis, p. 290-348,

Jacobson, M.Z. (2001). Strong radiative heating due to the mixing state of black carbon in atmospheric aerosols Letters to Nature, 409

Kaskaoutis, D.G and Kambezidis, H.D. (2006). Investigation on wavelength Dependence of the Aerosol Optical Depth in the Athens Area Q. Journal of Research Meteorology Society, 132: 2217-2234.

Kaufman, Y (1993). Aerosol optical thickness and path radiance Journal of Geophysical research 98 (D2) 2677-2692.

Kaufman, Y.J., Tanre, D., and Boucher, O, (2002). A satellite view of aerosols in the climate system, Nature, 419(6903; 215 - 223.

Kaufman, Y., Hobbs, P.V., Kirchhoff, V.W.J.H., Artaxo , P., Remer, L., Holben, B.N., King, M.D., Prins, E.M. Ward, D.E, Longo, K.M., Mattos, L.F., Nobre, C.A., Spinhirne, J., Thompson, A.M., Gleason, J.F. and Christopher, S. (1998). The Smoke Cloud and Radiation Experiment in Brazil (SCAR-B). Journal of Geophysical Research, 103 (D24)

Khatri, P., Ishizaka, Y and Takamura, T (2009). A study on aerosol optical properties in an urban atmosphere of Nagova. Journal of the Meteorology Society of Japan, 87: 19-38

King, M and Byrne, D (1976). A method for inferring total ozone content from the spectral variation of total optical depth obtained with a solar radiometer. Journal of Geophysical Research, 33: 3251-3254. 
Lau, K.M and Kim, K.M (2006). Observational relationships between aerosol and Asian monsoon rainfall and circulation Geophysical research letters, 33(21): L21810, doi:10.1029/2006GL027546.

Lignell, D.O., Chen, J. H., Smith, P.J., Lu, T., and Law, C.K (2007). The effect of flame structure on soot formation and transport in turbulent nonpremixed flames using direct numerical simulation, Combustion. Flame, 151(1-2): 2-28

Liou, K.N (2002).An introduction to Atmospheric Radiation $2^{\text {nd }}$ ed. Academic, San Diego, California.

Lockett, R.D and Wolley, R. (2007). Instability and soot formation in high-pressure Rich isooctane-air explosion flames, Combustion Flame, 151: 601-622

Lohmann, U. and feichter, J. (2005).Global indirect aerosol effect. a review, Atmospheric Chemistry and Physics, 5: 715-737

Lombaert, K., Le Moyne, L., De Maleissye, J.T. and Amouroux, J. (2006). Experimental study of $\mathrm{PAH}$ in engine soot by isotopic tracing Combustion Science and Technology, 178(4): 707-728.

Madronich, S. and Flocke, S. (1997). Theoretical estimation of biological effective UV radiation at earth's surface, in solar ultraviolet Radiation, edited by Zerefos, C.S. and Bais, A.F SpringerVerlag Berlin.

O'Neill, N. T and Royer, A (1993). Extraction of binomial aerosol-size distribution Radii from spectral and angular slope (Ångström) coefficients. Applied Optics, 32 1642-1645.

O'Neill, N., Dubovik, O and Eck, T (2001). Modified Angström exponent for the characterization of submicrometer. Applied Optics, 40(15): 23682375.

Paterson, R.I.A and Kraft, M. (2007). Models for the aggregate structure of soot particles, Combustion. Flame, 151(1-2): 160-172.

Pickett, L.M. and Siebers, D.L. (2004). Soot in diesel fuel jets. Effect of ambient temperature, ambient density and injection pressure. Combustion. Flame, 138(1-2): 114-135

Ramanathan, V and Carmichael, G (2008). Global and regional climate change due to black carbon. Nature Geoscience, 1: 221-227.

Ramanathan, V and Crutzen, P.J (2003). New directions atmospheric brown clouds. Atmospheric Environment, 37: 4033-4035.

Ranjan, R.R., Joshi, H.P and lyer, K.N (2007). Spectral variation of total column aerosol optical depth over Rajkot. A tropical semi-arid India Station. Aerosol and Air Quality Research 7: $33-45$

Reid, J.S., Jayaraman, A., Kiehl, J.T., Krishnamurti, T.N. and Lubin, D. (1999). Physical, chemical and optical regional hazes dominated by smoke in Brazil. Journal of Geophysical Research, 103: 32059-32080.

Reuder, J and Schwander, H (1999). Aerosol effects on UV radiation in nonurban regions. Journal of Geophysical Research, 104: 4065-4077.

Sagan, C and Pollack, J.B. (1967). Anisotropic nonconservative scattering and the clouds of Venus. Journal of Geophysics, 72(2): 469-477.

Schuster, G.L., Dubovik, O and Holben, B.N (2006). Ångström exponent and synthesis conditions. Combustion Flame, 136(1-2): 129-140.

Tang, I.N. (1996). Chemical and size effects of hygroscopic aerosol on light scattering Coefficients. Journal of Geophysical Research 101: 19245-19250.

Vander wal, R.L and Tomasek, A.J. (2004). Soot nanostructure. Dependence Upon synthesis conditions, Combustion Flame, 136: 129-140.

Watanabe, H., Kurose, R., Komori, S. and Pitsch, H. (2008). Effects of radiation on spray flame characteristics and soot formation. Combustion. Flame, 152(1-2): 2-13.

Wen, Z., Yun, S., Thompson, M.J., and Lightstone, M.F (2003).Modeling soot formation in turbulent kerosene/air jet diffusion flames. Combustion. Flame, 135(3): 323-340

Whitby, K. (1978). The physical characteristics of Sulfur aerosols. Atmospheric Environment, 12: 135-140. 